\title{
Abbreviations and Note on Translation
}

CCP Chinese Communist Party

GEMAS Guangzhou Enterprises Merges and Acquisitions Services

RMB Renminbi

SAIC Shanghai Automobile Industry Company

SOE State-owned enterprise

USD U.S. dollar

WTO World Trade Organization

The pinyin system for Romanizing Chinese characters is used throughout the text. Statements made in Cantonese are transcribed in Mandarin pinyin spelling. For scholars who publish in Chinese in China, I spell their names in the Chinese manner, that is, surname first and then given name. For scholars who publish in English, I spell their names in the English manner with surname at the end. 

Driving toward Modernity 
